\title{
Saxifraga damingshanensis (S. sect. Irregulares, Saxifragaceae), a new species from Guangxi, China
}

\author{
Wan-Yi Zhao,,*, Kai-Kai Meng',*, Qiang Fan', Jian-Hua Jin', Wen-Bo Liao' \\ I State Key Laboratory of Biocontrol and Guangdong Provincial Key Laboratory of Plant Resources, School of \\ Life Sciences, Sun Yat-sen University, Guangzhou 510275, China \\ Corresponding author: Wen-Bo Liao (1sslwb@mail.sysu.edu.cn); Jian-Hua Jin (1ssjjh@mail.sysu.edu.cn)
}

Academic editor: Doug Soltis | Received 2 June 2019 | Accepted 3 September 2019 | Published 16 October 2019

Citation: Zhao W-Y, Meng K-K, Fan Q, Jin J-H, Liao W-B (2019) Saxifraga damingshanensis (S. sect. Irregulares, Saxifragaceae), a new species from Guangxi, China. PhytoKeys 133: 95-103. https://doi.org/10.3897/ phytokeys.133.36704

\begin{abstract}
Saxifraga damingshanensis (Saxifragaceae), a new species from Damingshan Nature Reserve in Guangxi Province, is described and illustrated. A morphological comparison between the new species and its putative relatives, $S$. mengtzeana and $S$. luoxiaoensis, is presented. The new species is morphologically similar to $S$. mengtzeana, but it can be easily distinguished by its non-peltate leaf, both surfaces of mature leaf blade covered with white glandular trichome, petals 3-veined and margin entire. Phylogenetic analysis, based on two chloroplast DNA regions (matK and $p s b A-\operatorname{trn} H$ ), confirmed that the new species belongs to $S$. sect. Irregulares. The new species is currently only known from Damingshan, Guangxi and we assign it an IUCN Red List preliminary status as Data Deficient.
\end{abstract}

\section{Keywords}

China, chloroplast gene, phylogeny

\section{Introduction}

Saxifraga L. (Saxifragaceae) is widely distributed throughout the Northern Hemisphere and comprises ca. 440-450 species (Pan et al. 2001; Tkach et al. 2015a, b). Numerous previous molecular phylogenetic studies suggested that Saxifraga is monophyletic, providing that $S$. sect. Micranthes (Haw.) D.Don is excluded and the genus Micranthes Haw. recognised. (Soltis et al. 1996; Prieto et al. 2013; Deng et al. 2015; Tkach et al. 2015a, b). Saxifraga sect. Irregulares Haw., characterised by long-petiolate leaves, leaf-

\footnotetext{
* These authors contributed equally to this work.
}

Copyright Wan-Yi Zhao et al. This is an open access article distributed under the terms of the Creative Commons Attribution License (CC BY 4.0), which permits unrestricted use, distribution, and reproduction in any medium, provided the original author and source are credited. 
less flowering stems with small bracts, stamens with club-shaped filaments and pollen grains with numerous microchannels in the tectum, is the earliest-diverging named clade in Saxifraga (Soltis et al. 2001; Zhang et al. 2015; Tkach et al. 2015b).

In China, Saxifraga comprises 216 species, of which seven species belong to $S$. sect. Irregulares, according to the "Flora of China" (Pan et al. 2001). Recently, some new species of $S$. sect. Irregulares were discovered in China, including $S$. daqiaoensis F.W.Wang \& F.W.Xing (Wang et al. 2008), S. kegangii D.G.Zhang, Y.Meng \& M.H.Zhang (Zhang et al. 2017), S. luoxiaoensis W.B.Liao, L.Wang \& X.J.Zhang (Zhang et al. 2018) and S. shennongii L.Wang, W.B.Liao \& J.J.Zhang (Zhang et al. 2019).

During a botanical expedition to Damingshan National Nature Reserve, Wuming district, central Guangxi Province in September 2018, we discovered an unknown species of Saxifraga in Longtou Peak. Its mature leaves are densely covered with white trichomes and the abaxial surface is densely purple-spotted. After carefully checking specimens and literature, as well as morphological and molecular studies, we confirm that it is a new species of Saxifraga and it is described below.

\section{Materials and methods}

We collected more than 20 living individuals of the presumed new species for comparisons and taxonomical treatment. Specimens of Saxifraga sect. Irregulares, available at herbaria (PE, IBSC, SYS and IBK) and digital photos of all herbarium specimens of S. luoxiaoensis, S. mengtzeana Engl. \& Irmsch., preserved in the Chinese Virtual Herbarium (http://www.cvh.org.cn/), have been checked. Five main characters (leaf shape, leaf margin, spots on the abaxial surface of leaf, petal shape and trichomes on plants) of these three species were compared both in the wild and in the herbarium.

To determine the systematic position of Saxifraga damingshanensis, we further sampled five individuals of the presumed new species for a phylogenetic study. The geographic sampling information of these individuals was recorded by a Garmin GPS unit (GPSMAP 62sc, Taiwan) and the voucher specimens were deposited at Sun Yatsen University Herbarium (SYS) (Table 1). The final molecular dataset comprises 19 accessions representing eight species of $S$. sect. Irregulares, of which five accessions were newly generated and 14 accessions were downloaded from GenBank (Table 1).

The total DNA was extracted with the modified CTAB method (Doyle and Doyle 1987). The $p s b A-t r n H 2$ and matK intergenic regions were amplified using previously reported primers (Tate and Simpson 2003; Zhang et al. 2019). PCR amplifications were performed following Chen et al. (2016). Sequences were aligned with MEGA version 6.0 and subsequently manually adjusted (Tamura et al. 2013). Phylogenetic reconstructions were carried out with Maximum Likelihood (ML) and Bayesian Inference (BI) analyses. ML was run by IQ-Tree 1.6 .10 with 20,000 ultrafast bootstraps and SH-like approximate likelihood ratio test (aLRT) of 10,000 replicates (Nguyen et al. 2015). BI was executed in MrBayes version 3.2 (Ronquist et al. 2012), with four chains for at least 20,000,000 generations to make the average standard deviation of 
Table I. Voucher information and GenBank accession numbers for sequence data of Saxifraga damingshanensis phylogenetic analysis used in this study.

\begin{tabular}{lllc}
\hline \multicolumn{1}{c}{ Species } & \multicolumn{1}{c}{ Voucher } & matK & psbA-trnH2 \\
\hline Saxifraga damingshanensis & W. Y. Zhao 1208; Damingshan, Guangxi & MK976729 & MK976724 \\
& W. Y. Zhao 1209; Damingshan, Guangxi & MK976730 & MK976725 \\
& W. Y. Zhao 1210; Damingshan, Guangxi & MK976731 & MK976726 \\
& W. Y. Zhao 1211; Damingshan, Guangxi & MK976732 & MK976727 \\
& W. Y. Zhao 1212; Damingshan, Guangxi & MK976733 & MK976728 \\
Saxifraga mengtzeana & FHZ-1608; Yuanbao Mountion, Guangxi & MK092518 & - \\
Saxifraga rufescens & YLDP197D; Yulong Mountion, Yunnan & MH116857 & MH117313 \\
Saxifraga stolonifera & LXP-13- 24775(1); Yanling country, Hunan & MK092557 & MK092599 \\
& LXP-13-24775(2); Yanling country, Hunan & MK092558 & MK092600 \\
& LXP-13- 24775(3); Yanling country, Hunan & MK092551 & MK092593 \\
& LXP-13-24775(4); Yanling country, Hunan & MK092552 & MK092594 \\
Saxifraga epiphylla & Q. Fan 15680(1); Qingchengshan, Sichuan & MK092519 & - \\
& Q. Fan 15680(2); Qingchengshan, Sichuan & MK092520 & - \\
Saxifraga daqiaoensis & RY-2017-031(1); Daqiao Town, Guangdong & MK092533 & MK092575 \\
& RY-2017-031(2); Daqiao Town, Guangdong & MK092534 & MK092576 \\
Saxifraga luoxiaoensis & LXP-13-24717(1); Nanfengmian, Jiangxi & MK092539 & MK092581 \\
& LXP-13-24717(2); Nanfengmian, Jiangxi & MK092540 & MK092582 \\
Saxifraga shennongii & LXP-13-24778(1); Yanling country, Hunan & MK092527 & MK092569 \\
& LXP-13-24778(2); Yanling country, Hunan & MK092528 & MK092570 \\
& LXP-13-24769(1); Yanling country, Hunan & MK092521 & MK092563 \\
& LXP-13-24769(2); Yanling country, Hunan & MK092522 & MK092564 \\
\hline
\end{tabular}

*All vouchers are deposited in the Sun Yat-sen University Herbarium (SYS); "l" represents missing data.

split frequencies (ASDFs) < 0.01, sampling every 1000 generations with the first 25\% sampled trees discarded as burn-in. The $50 \%$ majority-rule consensus trees were finally generated. For both ML and BI analyses, F81+F+I was detected as the best-fitting nucleotide substitution model on the basis of Bayesian Information Criterion (BIC) detected by ModelFinder (Kalyaanamoorthy et al. 2017).

\section{Results}

\section{Morphological comparison}

In morphology, the putative new species is closely related to Saxifraga mengtzeana and their morphology comparisons are presented in Table 2. These two species share such features as having stolons absent, inflorescences and pedicels covered with glandular hairs, white flowers without pink markings and base of three short petals with yellow plot. However, the new species differs from $S$. mengtzeana by having leaf base cordate to deep cordate (vs. usually peltate), leaves papery or nearly leathery (vs. leathery), adaxial surface of the mature leaf with glandular trichome (vs. nearly glabrous) and longest petal 3-veined, margin entire (vs. 8-veined, margin sparsely denticulate). Moreover, $S$. damingshanensis flowers from August to October, while $S$. mengtzeana flowers from March to August. 
Table 2. Morphological comparisons amongst Saxifraga damingshanensis, S. luoxiaoensis and S. mengtzeana.

\begin{tabular}{|c|c|c|c|}
\hline Characters & Saxifraga damingshanensis & S. luoxiaoensis & S. mengtzeana \\
\hline Leaf shape & rounded or ovate, never peltate & reniform, never peltate & \pm peltate, ovate \\
\hline Leaf texture & papery or leathery & papery & leathery \\
\hline Leaf base & cordate to deep cordate & cordate & \pm cordate \\
\hline Leaf margin & $\begin{array}{l}\text { 5-10-lobed, lobes entire, } \\
\text { sparsely glandular hairy }\end{array}$ & $\begin{array}{c}\text { margin } 7-9 \text {-lobed, usually } \\
\text { double serrate }\end{array}$ & $\begin{array}{l}\text { crenate, inconspicuous } \\
\text { glandular hairy }\end{array}$ \\
\hline $\begin{array}{l}\text { Abaxial surface of } \\
\text { leaf blade }\end{array}$ & $\begin{array}{l}\text { with glandular trichome and } \\
\text { purple spots }\end{array}$ & $\begin{array}{l}\text { glabrous with red or brown } \\
\text { spotted }\end{array}$ & $\begin{array}{l}\text { sparsely hispid and brown } \\
\text { spotted }\end{array}$ \\
\hline $\begin{array}{l}\text { Second longest } \\
\text { petal }\end{array}$ & $\begin{array}{c}\text { lanceolate oblong, } 13-17 \times 2 \\
\mathrm{~mm}, 3 \text {-veined }\end{array}$ & $\begin{array}{l}\text { lanceolate oblong, ca. } \\
\text { 8-20 } \mathrm{mm} \times 1.3-3 \mathrm{~mm} \text {, } \\
\text { 3-5-veined }\end{array}$ & $\begin{array}{c}\text { narrowly ovate, ca. } 9 \times 2.2 \mathrm{~mm} \text {, } \\
\text { 3-veined }\end{array}$ \\
\hline First longest Petal & $\begin{array}{c}\text { lanceolate, } 1.8-2.2 \mathrm{~cm} \times \\
1.5-2.5 \mathrm{~mm}, 3 \text {-veined, margin } \\
\text { entire }\end{array}$ & $\begin{array}{c}\text { linear lanceolate, } 16-25 \mathrm{~mm} \\
\times 1.3-3 \mathrm{~mm}, 3-5 \text {-veined, } \\
\text { margin entire }\end{array}$ & $\begin{array}{c}\text { sublanceolate, } 19 \times 3.4 \mathrm{~mm} \text {, } \\
\text { 8-veined, margin sparsely } \\
\text { denticulate }\end{array}$ \\
\hline Stamens & $3.5-4.5 \mathrm{~mm}$ long & $4.3-5.6 \mathrm{~mm}$ long & ca. $6 \mathrm{~mm}$ long \\
\hline Flowering period & August to October & April to June & May to August \\
\hline
\end{tabular}

\section{Phylogenetic placement of Saxifraga damingshanensis within S. sect. Irregulares}

The concatenated sequences of matK $(740 \mathrm{bp})$ and $p s b A-\operatorname{trn} H 2(297 \mathrm{bp})$ are $1037 \mathrm{bp}$ in length and 81 parsimony-informative sites were detected. Our results showed that S. ser. Rufescentes J.T.Pan is monophyletic (SH-aLRT: 100; LP: 100; PP: 1.00, Fig. 1) which is coincident with the previous study (Zhang et al. 2018). The putative new species, $S$. damingshanensis, was nested into $S$. ser. Rufescentes J.T.Pan and was strongly supported as sister to a clade consisting of $S$. luoxiaoensis, $S$. daqiaoensis and $S$. shennongii (SH-aLRT: 97; LP: 98; PP: 1.0).

\section{Discussion}

Based on its basal leaves with long petiolate, flower zygomorphic and stamens with club-shaped filaments, the new species could be placed within $S$. sect. Irregulares. Our phylogeny also supports the inclusion of Saxifraga damingshanensis within S. sect. Irregulares (Fig. 1). All examined individuals of $S$. damingshanensis clustered into a single lineage, thus corroborating the evidence for the new species status, based on morphology.

Our study also recovered a sister relationship of the new species with a clade comprising Saxifraga luoxiaoensis, S. daqiaoensis and S. shennongii. The close relationship amongst these species was also supported by their similar morphological characteristics. All four species have white glandular trichomes on leaf and inflorescence and white and entire petals. However, $S$. damingshanensis differs from the latter three species by having mature leaf and petiole with glandular trichomes (vs. mature leaf sparsely hispid or glabrous) and the abaxial surface of the leaf blade with purple spots (vs. usually yellow-brown spots). Furthermore, their phenology and distribution are different. Saxifraga damingshanensis is flowering from August to October (vs. April to June) and endemic to Damingshan, Guangxi (vs. Guangdong, Jiangxi and Hunan). 


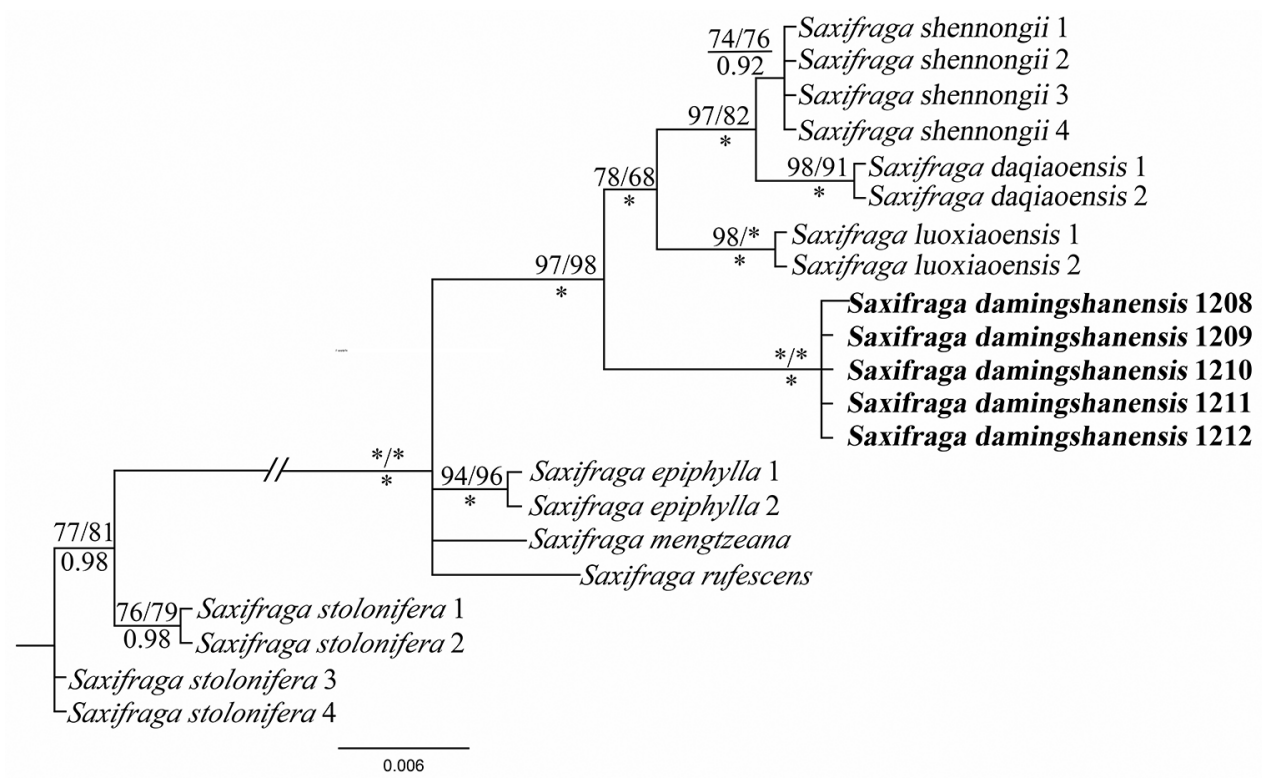

Figure I. Bayesian consensus tree of Saxifraga damingshanensis and related species derived from two chloroplast regions. Numbers above branches are the value of SH-like approximate likelihood ratio test (aLRT) and bootstrap value of the Maximum Likelihood (LP); numbers below branches indicate Bayesian posterior probability (PP). Asterisks denoted $\left(^{*}\right)$ the values of 100 or 1.00 for LP/PP. The new species is shown in bold.

\section{Taxonomic treatment}

\section{Saxifraga damingshanensis W.B.Liao, W.Y.Zhao \& J.H.Jin, sp. nov.} urn:lsid:ipni.org:names:77202383-1

大明山虎耳草

Type. China. Guangxi: Nanning city, Damingshan Nature Reserve, Longtou Peak, $23^{\circ} 22^{\prime} 58.48^{\prime \prime N}, 108^{\circ} 30^{\prime} 21.56 " \mathrm{E}, 1542 \mathrm{~m}$ alt., 19 September 2018, W.Y.Zhao 1208 (Holotype SYS!; Isotypes SYS!, IBSC!). (Fig. 2)

Diagnosis. Saxifraga damingshanensis is morphologically most similar to S. mengtzeana, but differs by its leaf blade with glandular trichome and purple spots abaxially, short stamens and petal entire.

Description. Perennial herbs, $15-30 \mathrm{~cm}$ tall. Stolons absent. Rhizomes rather short (ca. 0.3-0.7 cm), sparsely glandular trichomes. Basal leaves forming a rosette, petiole 5-15 $\mathrm{cm}$ long, fleshy and translucent, sparsely short glandular trichomes (ca. $2 \mathrm{~mm}$ ); petiole base sheathed, margin with sparsely glandular trichomes; leaf blade rounded or ovate, base cordate to deep cordate, papery or leathery, $2.0-5.7 \times 2.5-5.5 \mathrm{~cm}$, apex obtuse, margin inconspicuous 7-15-lobed with sparsely glandular trichomes, lobes entire, adaxially dark green, densely covered glandular trichomes $(2.5-4 \mathrm{~mm})$, abaxially grey, sparsely covered with glandular trichomes $(1.5-2.5 \mathrm{~mm})$, densely covered with purple spots; palmate veins 7-11, both surfaces inconspicuous. Cauline leaves 1-2, triangular-lanceolate, 5.0-6.0 × 

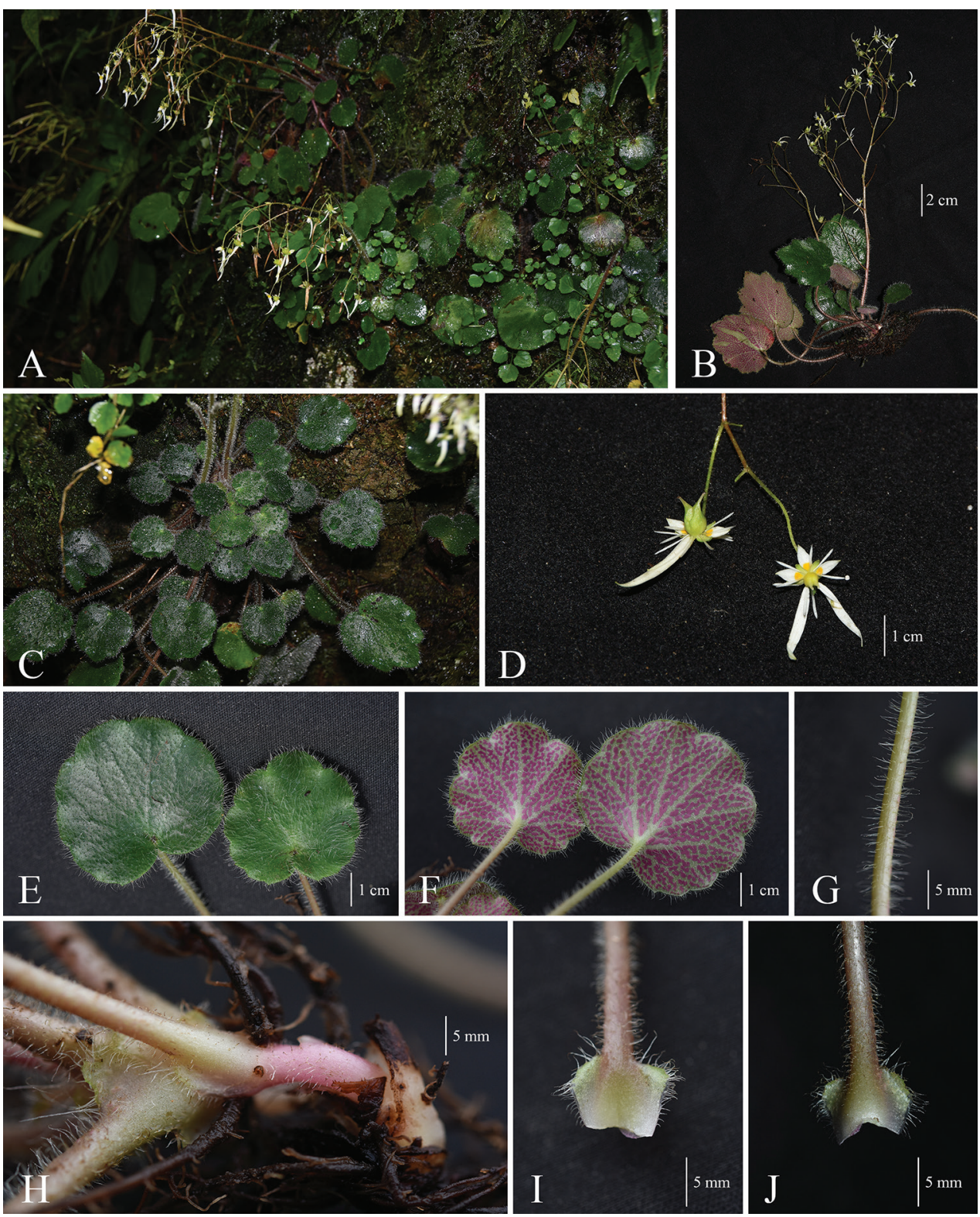

Figure 2. Saxifraga damingshanensis $\mathbf{A}$ Habit $\mathbf{B}$ whole plant $\mathbf{C}$ basal leaves rosette with long petiole, plant cover white trichomes $\mathbf{D}$ flower and fruit, pedicel slender with short trichomes, filaments clavate $\mathbf{E}$ adaxial leaf surface dark green, sparsely glandular piliferous $\mathbf{F}$ abaxial leaf surface grey, sparsely glandular piliferous and purple spotted $\mathbf{G}$ petiole with glandular piliferous $\mathbf{H}$ rhizomes cover sparsely glandular piliferous, petiole base sheathed I adaxial surface of sheath, glabrous, margin with glandular piliferous $\mathbf{J}$ abaxial surface of sheath, upper with sparse glandular piliferous. 
1.5-2.0 mm, margin with sparsely glandular trichomes. Inflorescence paniculate, 15$30 \mathrm{~cm}$ long, 10-35-flowered; branches $4-5 \mathrm{~cm}$, sparsely short glandular trichomes (0.5$1.0 \mathrm{~mm}), 2-6(-8)$-flowered; pedicels slender, $1.5-2.5 \mathrm{~cm}$ long, sparsely short glandular trichomes (ca. $0.5 \mathrm{~mm}$ ); bracts linear, $1.5-2.5 \times 0.5-0.8 \mathrm{~mm}$, margin with short glandular trichomes. Flowers zygomorphic; sepals 5, spreading, narrowly ovate, $2.0-2.5 \times 1.0 \mathrm{~mm}$, apex obtuse, base connate, adaxially glabrous, abaxial surface and margin with sparsely short glandular trichome, becoming denser proximally, 3 veins inconspicuous. Petals 5 , white; shortest 3 petals equal, ovate, base with yellow spots, 3-3.5 $1.5 \mathrm{~mm}$, apex acute, base rounded, triplinerved; the other two petals lanceolate, first longest petal lanceolate, 18-22 × 1.5-2.5 mm, apex acuminate, margin entire, glabrous, 3-veined; second longest petal narrowly ovate, $1.3-1.7 \times 0.2 \mathrm{~cm}$, apex acuminate, margin entire, glabrous, 3-veined. Stamens 10, filaments clavate, 3.5-4.5 mm long. Ovary ovoid, 1.5-2.5 mm long; disc obscure; carpels 2, proximally connate about 3/4; styles 2, divergent, $1.5-2 \mathrm{~mm}$ long. Capsule ovoid, 4-5 × 3-4 mm. Seeds elongate-ellipsoid, yellowish-brown or dark brown, the two ends slightly bent, ca. $0.6 \mathrm{~mm}$, surface 3 -ribbed.

Phenology. Flowering from August to October, fruiting from September to November.

Etymology. The species epithet is based on the mountain name, Damingshan and the Latin suffix, -ensis, of origin, where the new species was collected.

Distribution, ecology and conservation status. Only three populations of Saxifraga damingshanensis were discovered from Damingshan National Nature Reserve, Guangxi Province. It was observed to grow on damp cliffs and rocks in broad-leaved forests at altitudes between 1300 and $1650 \mathrm{~m}$. Its known localities are well protected and more field investigations are needed to determine its wild distribution. Therefore, we suggest listing the new species as Data Deficient (DD) based on the IUCN Red List Criteria (IUCN 2019).

Additional specimens examined (paratypes). China. Guangxi: Nanning city, Damingshan Nature Reserve, Longtou Peak, Blackwood cliff, 23⒉ $22^{\prime} 58.48 " \mathrm{~N}$, $108^{\circ} 30^{\prime 2} 21.56$ "E, $1542 \mathrm{~m}$ alt., 19 September 2018, W.Y.Zhao 1209 (SYS!); same locality, $1500 \mathrm{~m}$ alt., 19 September 2018, W.Y.Zhao 1210 (SYS!); same locality, $1522 \mathrm{~m}$ alt., 19 September 2018, W.Y.Zhao 1211 (SYS!); same locality,1480 m alt., 19 September 2018, W.Y.Zhao 1212 (SYS!); Wuming county, Xiaolu village, Damingshan, $1420 \mathrm{~m}$ alt., 26 August 1958, Y.C.Chen 325 (IBK18155!).

\section{Acknowledgements}

We thank Fan Ye and Bao-Huan Wu for the field work. We thank Su-Juan Wei and Ping Yang for providing images of herbarium specimens in IBK. We are grateful to KeWang $\mathrm{Xu}$ and two reviewers for the valuable comments and suggestions on the manuscript. This study was supported by the Basic Work Special Project of the National Ministry of Science and Technology of China (2013FY111500) and the project of the Fourth Survey of Chinese Traditional Medicine Resources (2018-523-001). 


\section{References}

Chen YP, Drew BT, Li B, Soltis DE, Soltis PS, Xiang CL (2016) Resolving the phylogenetic position of Ombrocharis (Lamiaceae), with reference to the molecular phylogeny of tribe Elsholtzieae. Taxon 65(1): 123-136. https://doi.org/10.12705/651.8

Deng J, Drew BT, Mavrodiev EV, Gitzendanner MA, Soltis PS, Soltis ED (2015) Phylogeny, divergence times, and historical biogeography of the angiosperm family Saxifragaceae. Molecular Phylogenetics and Evolution 83: 86-98. https://doi.org/10.1016/j. ympev.2014.11.011

Doyle JJ, Doyle JL (1987) A rapid DNA isolation procedure for small quantities of fresh leaf tissue. Phytochemical Bulletin 19: 11-15.

IUCN (2019) Guidelines for Using the IUCN Red List Categories and Criteria. Version 14. Prepared by the Standards and Petitions Committee. http://www.iucnredlist.org/documents/RedListGuidelines.pdf

Kalyaanamoorthy S, Minh BQ, Wong TKF, von Haeseler A, Jermiin LS (2017) ModelFinder: Fast model selection for accurate phylogenetic estimates. Nature Methods 14(6): 587-589. https://doi.org/10.1038/nmeth.4285

Nguyen LT, Schmidt HA, von Haeseler A, Minh BQ (2015) IQ-TREE: A fast and effective stochastic algorithm for estimating maximum likelihood phylogenies. Molecular Biology and Evolution 32(1): 268-274. https://doi.org/10.1093/molbev/msu300

Pan JT, Gu CZ, Huang SM, Wei ZF, Jin SY, Lu LD, Akiyama S, Alexander C, Bartholomew B, Cullen J, Gornall RJ, Hultgård U-M, Ohba H, Soltis DE (2001) Saxifragaceae. In: Wu ZY, Raven PH, Hong DY (Eds) Flora of China, vol. 8. Science Press, Beijing and Missouri Botanical Garden Press, St. Louis, 269-452. http://foc.eflora.cn/content. aspx? TaxonId= 10800

Prieto JAF, Arjona JM, Sanna M, Pérez R, Cires E (2013) Phylogeny and systematics of Micranthes (Saxifragaceae): An appraisal in European territories. Journal of Plant Research 126: 605-611. https://doi.org/10.1007/s10265-013-0566-2

Ronquist F, Teslenko M, Ayres DL, Darling A, Höhna S, Larget B, Liu L, Suchard MA, Huelsenbeck JP (2012) MrBayes 3.2: Efficient Bayesian phylogenetic inference and model choice across a large model space. Systematic Biology 61(3): 539-542. https://doi.org/10.1093/ sysbio/sys029

Soltis DE, Kuzoff RK, Conti E, Gornall R, Ferguson K (1996) matK and rbcL gene sequence data indicate that Saxifraga (Saxifragaceae) is polyphyletic. American Journal of Botany 83(3): 371-382. https://doi.org/10.1002/j.1537-2197.1996.tb12717.x

Soltis DE, Kuzoff RK, Mort ME, Zanis M, Fishbein M, Hufford L, Koontz J, Arroyo MK (2001) Elucidating deep-level phylogenetic relationships in Saxifragaceae using sequences for six chloroplastic and nuclear DNA regions. Annals of the Missouri Botanical Garden 88(4): 669-693. https://doi.org/10.2307/3298639

Tamura K, Stecher G, Peterson D, Filipski A, Kumar S (2013) MEGA6: Molecular evolutionary genetics analysis version 6.0. Molecular Biology and Evolution 30(12): 2725-2729. https://doi.org/10.1093/molbev/mst197 
Tate JA, Simpson BB (2003) Paraphyly of Tarasa (Malvaceae) and diverse origins of the polyploid species. Systematic Botany 28(4): 723-737. https://doi.org/10.1043/02-64.1

Tkach N, Röser M, Hoffmann MH (2015a) Molecular phylogenetics, character evolution and systematics of the genus Micranthes (Saxifragaceae). Botanical Journal of the Linnean Society 178(1): 47-66. https://doi.org/10.1111/boj.12272

Tkach N, Röser M, Miehe G, Muellner-Riehl AN, Ebersbach J, Favre A, Hoffmann MH (2015b) Molecular phylogenetics, morphology and a revised classification of the complex genus Saxifraga (Saxifragaceae). Taxon 64(6): 1159-1187. https://doi.org/10.12705/646.4

Wang GF, Ye YS, Xing FW (2008) Saxifraga daqiaoensis (Saxifragaceae), a new species from Guangdong, China. Annales Botanici Fennici 45(3): 237-239. https://doi. org/10.5735/085.045.0313

Zhang ZX, Chen SL, Gornall RJ (2015) Morphology and anatomy of the exine in Saxifraga (Saxifragaceae). Phytotaxa 212(2): 105-132. https://doi.org/10.11646/phytotaxa.212.2.1

Zhang MH, Zhang XS, Nie ZL, Zhang DG, Meng Y (2017) Saxifraga kegangii (Saxifragaceae), a new species from Hunan Province of central China. Phytotaxa 309(2): 159-165. https:// doi.org/10.11646/phytotaxa.309.2.7

Zhang XJ, Liu ZC, Meng KK, Ding QL, Wang L, Liao WB (2018) Saxifraga luoxiaoensis (Saxifragaceae), a new species from Hunnan and Jaingxi, China. Phytotaxa 350(3): 291-296. https://doi.org/10.11646/phytotaxa.350.3.8

Zhang JJ, Zhao WY, Meng KK, Liao WB, Wang L, Chen SF (2019) Saxifraga shennongii, a new species of Saxifragaceae from Hunan Province, China. Phytotaxa. [in press] 